\title{
Anti-inflammatory and Regenerative Effects of Albanian Propolis in Experimental vital Amputations in Piglets (Histological assessment)
}

\author{
Aida Meto ${ }^{1}$, Agron Meto $^{2}$, Emiljano Tragaj ${ }^{3}$, Mutlu Özcan ${ }^{4}$ \\ ${ }^{1,2,3}$ University of Aldent, Faculty of Medicine, Department of Dentistry, Section of Endodontics, Histological and Bacteriological \\ Laboratory, Tirana, Albania
}

${ }^{4}$ University of Zurich, Dental Materials Unit, Center for Dental and Oral Medicine, Clinic for Fixed and Removable Prosthodontics and Dental Materials Science, Zurich, Switzerland

\begin{abstract}
This study evaluated the effects of Albanian propolis on the inflamed pulpal tissue after pulpotomy in piglets. Pulpotomy was made in the maxillary and mandibular central and lateral incisors. Microbial flora pathogenesis prepared from the section of infected teeth, containing Staphylococcus aureus, Streptococcus viridans, Enterococcus faecalis, Staphylococcus albus and mixed flora were used to cause artificial pulpitis. The first group consisted of piglets with teeth having pulpal inflammation and regeneration without medication served as a control group. In the second group, the teeth were treated with pure propolis after vital amputation. In the $3^{\text {rd }}$, $4^{\text {th }}$ and $5^{\text {th }}$ groups, the teeth were treated after vital amputation with the compounds of $\mathrm{ZnO}+10 \%$, $\mathrm{ZnO}+20 \%$ propolis in ethanol, and with the paste composed of $\mathrm{Ca}(\mathrm{OH})_{2}+30 \%$ oily propolis, respectively. Histopathology analyses were performed to survey the infected pulp tissue treated with propolis up to 3 months. After vital amputation of the pulp, application of Albanian propolis showed significantly higher anti-inflammatory and regenerative effect creating dentin barrier after 3 months of treatment compared to control group $(p<0.05)$. These results were more expressed in the group containing $20 \%$ propolis in ethanol $+\mathrm{ZnO}$.
\end{abstract}

Keywords: amputation, dentin bridge, inflammation, propolis, regeneration

\section{Introduction}

The objectives of this study therefore were to observe the anti-inflammatory and regenerative action of Albanian propolis on the pulp tissue after vital amputation in vivo in piglets.

Pulp pathology is one of the major concerns dentistry in that the incidence of complications following pulpitis have been largely treated with pulpectomy only. ${ }^{[3],[8],[9]}$ In fact keeping pup vital or regenerate the infected pulp could eliminate tooth extraction and thereby avoid subsequent surgical or reconstructive solutions. Regardless of the methods used for traditional endodontic treatment, the failure rate over time ranges from 30 to $40 \% .{ }^{[3],[9]}$ In this regard, some attempts have been made to treat pulpal pathology utilizing curative properties of propolis based pastes used in vital amputation one of which is Albanian propolis. The physico-chemical and organoleptic parameters of the Albanians propolis listed as follows: the typical smell, yellow-green color, bitterness, $25-35 \%$ wax in its composition, fusion temperature between 65-82 ${ }^{\circ} \mathrm{C}$, amount dissolved in chloroform 7.64- 22:44\%, oxidation index of 16-21 seconds, approximately $18.2 \%$ amount of mechanical impurities, unsaturated acids permanent components of the propolis, being thermostatic (resistance to boiling in water for $1 \mathrm{~h} 20$ minutes), autoclavable, insolubility in water, $87 \%$ solubility in ethanol, indigestible wax amount of 13:26\%, soluble wax amount of $71.28 \%$, clear liquid extract translucent, dark-brown hue, balsamic aromatic odor, bitter spicy taste, numbing and styptic, $0.05 \%$ number of disturbance, dry residue of $22.5 \%$, 0.966 specific gravity, $60 \%$ extract content of ethanol and a $\mathrm{pH}$ of 4.9 to 5 .

\section{Literature Survey}

Other propolis types investigated worldwide has similar properties with those of Albanian propolis. ${ }^{[1],[5],[12],[14]}$

Propolis is a natural medicament with anti-microbial, antiinflammatory, anti-fungal, immunomodulatory and regenerative properties and its curative features are comparable to those of the antibiotics. ${ }^{[4],[10],[13],[17]}$ This resinous substance, varying in color from yellow-brown to dark-brown, is collected from trees and shrubs by honeybees. The main chemicals present in propolis are flavonoids, phenolic and other various aromatic compounds. Flavonoids are well-known plant compounds that have antioxidant, antibacterial, antifungal, antiviral and anti-inflammatory properties. $^{[1],[6],[16]}$ Propolis as an anti-inflammatory agent has also been shown to inhibit synthesis of prostaglandins. In addition, it contains elements such as iron and zinc that are important for the synthesis of collagen, ${ }^{[2],[5]}$ and supports the immune system by promoting phagocytic activities, stimulating cellular immunity and augmenting healing effects. Hence, it could be anticipated that Albanian propolis could show regenerative effects in experimental vital amputations.

\section{Materials and Method}

\section{Animals}

The experiments were performed at the histopathology laboratories of the University of Medicine Tirana, Albania. The study was performed in accordance with the protocol approved by the Animal Care and Use Committees of University of Medicine, Tirana, Albania. The piglets were obtained from the Institute of Animal Science of the 


\section{International Journal of Science and Research (IJSR) \\ ISSN (Online): 2319-7064 \\ Index Copernicus Value (2013): 6.14 | Impact Factor (2015): 6.391}

Agricultural University of Tirana, Albania. Permanent maxillary and mandibular incisors were identified and the cavities were opened in cervical-vestibular direction in matriculated piglets ( $\mathrm{N}=25,5$ per group). In each piglet 2 teeth were included in the study yielding to 10 teeth per group. The treatment procedure started in the $2^{\text {nd }}$ month after birth when the piglets weighed 6 to $7 \mathrm{~kg}$. All piglets were sacrificed when they were 3 months old and weighed $20 \mathrm{~kg}$.

\section{Experimental Procedures}

Solutions of propolis and propolis based curative pastes were prepared in two different ways. Initially, liquid alcohol was extracted from Albanian crude propolis under laboratory conditions, which was then evaporated to prepare a soft and dry extract of propolis as described previously. In order to achieve this, first propolis were cut into pieces and partitioned using scissors and fine separators. It was then dissolved in $90 \%$ ethanol and filtered by extraction. Extraction was conducted using a device that consisted in a distilling pot having stainless double walls allowing the circulation in water between $70-80^{\circ} \mathrm{C}$ under vacuum. Evaporation in vacuum and moderate warming ensure the preservation of active ingredients of the propolis. Condensed material was then collected in a glass pot connected to the vacuum extraction device. The amount of the solvent was reduced reaching $20 \%$ of $90 \%$ ethanol. Starting with the soft and dry extract of propolis, $10 \%$ and $20 \%$ alcoholic propolis solutions were prepared and $30 \%$ propolis was dissolved in vegetable oil. This type of oil was used to be mixed with $\mathrm{Ca}(\mathrm{OH})_{2}$, unlike ethanol which immediately causes solidification of the $\mathrm{Ca}(\mathrm{OH})_{2}$. The teeth selected for the experiments were injured under local anesthesia using an aerator with distilled water with round bur. They were then infected with microbial flora pathogenesis prepared from the section of infected teeth, containing Staphylococcus aureus, Streptococcus viridans, Enterococcus faecalis, Staphylococcus albus and mixed flora to cause pulpitis. ${ }^{[10],[11]}$

The first group consisted of piglets with the teeth that where pulpal inflammation was induced. This group served as the control group. In the second group, the teeth were treated with pure propolis after vital amputation. In the $3^{\text {rd }}, 4^{\text {th }}$ and $5^{\text {th }}$ groups, the teeth were treated after vital amputation with the compound of $\mathrm{ZnO}+10 \%, \mathrm{ZnO}+20 \%$ propolis in ethanol, and with the paste composed of $\mathrm{Ca}(\mathrm{OH})_{2}+30 \%$ oily propolis, respectively.

The vital amputation of coronal pulp was performed under anesthesia using mepivacaine hydrochloride $3 \%$ in all cases. After stopping the pulpal hemorrhage using physiological solution and sterile tampons in conditions of full asepsis, a net $3 \mathrm{~g}$ amount of propolis and other curative pastes that contained zinc oxide and calcium hydroxide in sufficient thickness, were placed on the pulp without applying pressure. Treated cavities were isolated with glass-ionomer cement and were obturated by chemically-polymerized resin composite.

The teeth in all groups were observed for a period of three months after the infection and the treatment. Piglets were sacrificed for histological examinations in the relevant laboratory after three months of observation. Experienced pathologists evaluated the sections dyed with HematoxylinEosin, Trichrome Vert and Van Gieson.

\section{Histological assessment of pulp response and dentin regeneration}

Three months following pulp capping, the teeth were fixed in $10 \%$ formalin and decalcified in 10 to $15 \%$ ethylenediaminetetraacetic acid. Sections of 5 to $6 \mathrm{~mm}$ thickness from the embedded specimen were stained with Hematoxylin-Eosin. One blinded histologist, analyzed the area of mineralization semi-quantitatively using histomorphometric techniques. Propolis treated specimens were fixed in $10 \%$ formalin and decalcified. After they were embedded in paraffin, the specimens were cut by microtome and coloured using Hematoxylin-Eosin dyes. Microscopy examinations were finally performed using a microscope at x400 magnification.

\section{Results}

All the groups of piglets involved in the experiment showed normal development and were in good health until they were sacrificed. We extracted the teeth after 2 hours, 5 and 7 days after the treatment procedures. The histological analysis of the teeth two hours after the injury and infection, presented acute active hyperemia, accompanied by pronounced dilatation of coronary capillaries of the pulp, and polymorphonuclear cells [Fig. 1]. After 5 and 7 days following injury, coronary purulent inflammation was present in more than $50 \%$ of the cases [Figs. 2-3].

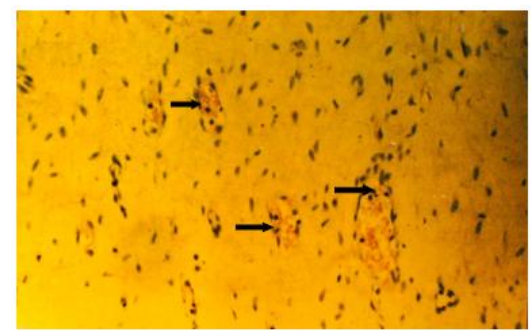

Figure 1: Two hours after injury and infection, died with hematoxylin-eosin showing acute active hyperemia $(\rightarrow)$.

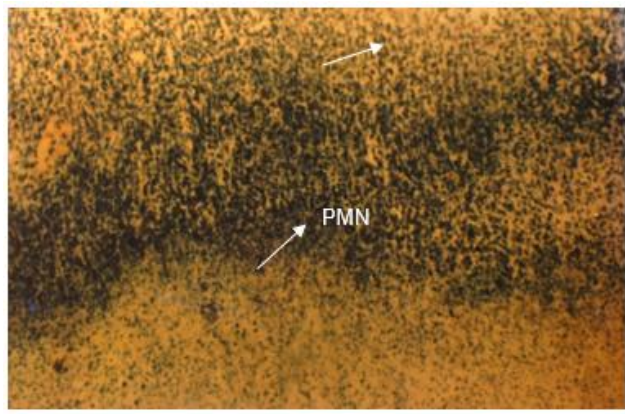

Figure 2: After 5 days of infection. Note the polymorphonuclear cells (PMN) and acute purulent inflammation $(\rightarrow)$. 


\section{International Journal of Science and Research (IJSR) \\ ISSN (Online): 2319-7064}

Index Copernicus Value (2013): 6.14 | Impact Factor (2015): 6.391

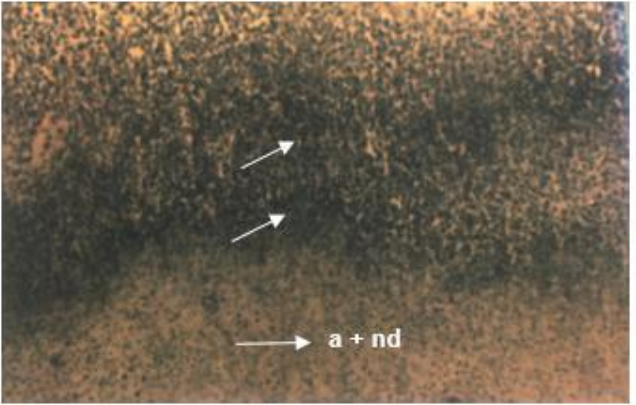

Figure 3: After 7 days of infection. Note the dense infiltrate with inflammatory cells (abscesses-a and necrotic detritusnd) restricted in granulation tissue.

In the second group, where pure propolis was used formation of dentine bridges in the vicinity of the paste were evident. After three months, histological examinations, showed normal height of the treated teeth and no changes in the periodontal ligament. No necrosis was identified between the paste and the dentin bridges. Histological analysis revealed the presence of dentin bridges with no channels of odontoblasts palisades and fibrotic tissue. The pulp in the apical part was normal in all cases [Figs. 4-5].

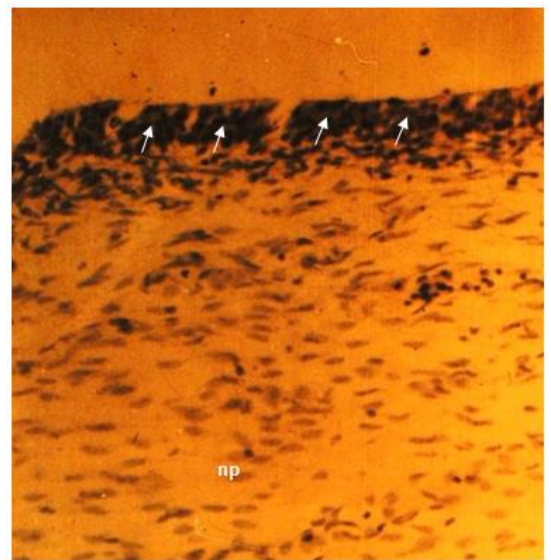

Figure 4: 3 months after treatment (normal pulp-np), $(\rightarrow)$ odontoblasts palisades (dyed with Hematoxylin-Eosin)

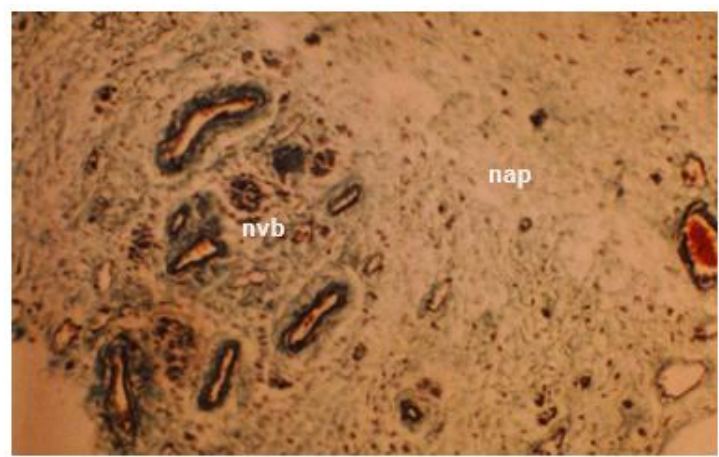

Figure 5: 3 months of treatment (normal apical pulp-nap), neuro vascular bundles (nvb) dyed with Trichrome Vert.

The third group treated with the paste of $10 \%$ zinc oxide propolis solution. Histological examinations showed presence of dentin bridges in $80 \%$ of the cases. Secondary dentin was observed in the upper part where the borders of odontoblasts were slightly destroyed. While slight chronic inflammation in the pulp at the borders was observed, the pulp in the apical region was normal [Fig. 6].

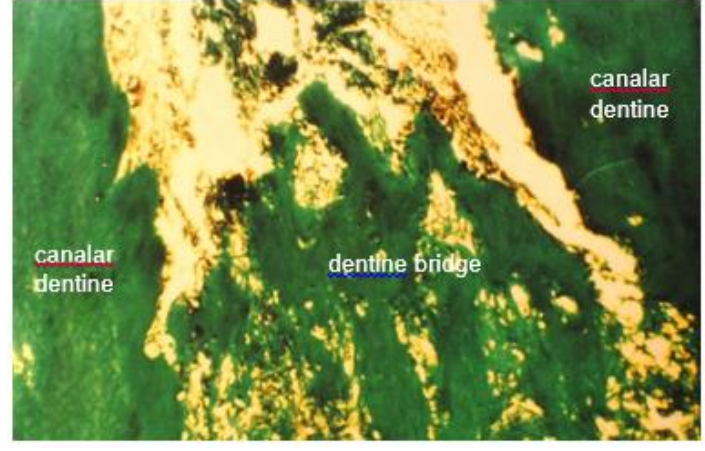

Figure 6: 3 months after treatment dyed with Trichrome Vert.

In the fourth group treated with the paste consisting $20 \%$ propolis and zinc oxide. Histological examinations of solutions showed normal apical pulp and the existence of blood capillaries in the pulp. The borders of odontoblasts showed regular palisade positioning. Finally, new dentin with no channels was noticed in the borders [Fig. 7]. Dentin bridges were very well supported by the walls of the radicular channel in all the cases of the fourth group [Fig. 8].

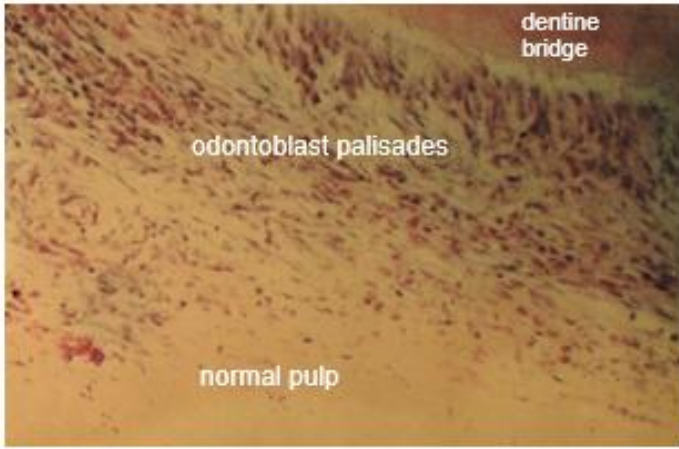

Figure 7: 3 months after treatment (normal pulp), odontoblast palisades and dentin bridge formation (dyed with Hematoxylin-Eosin).

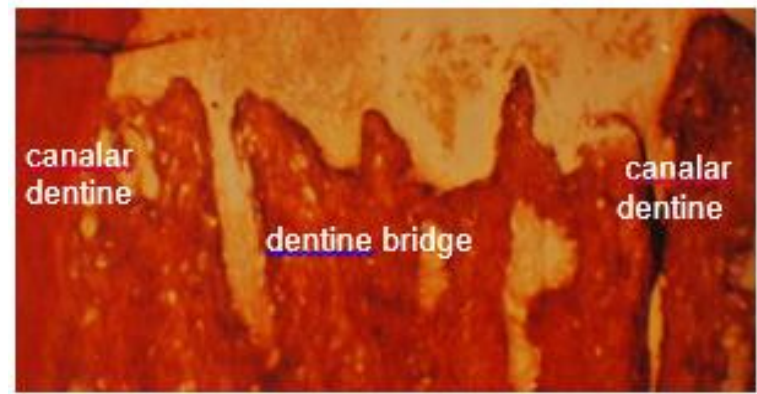

Figure 8: 3 months after treatment showing canal dentin, dentin bridge dyed with Van Gieson

In the fifth group treated with calcium hydroxide and $30 \%$ oily propolis, immediately after application of the paste. The histological analysis showed dystrophic processes in the pulp, fibrosis of the pulp, partial dentin bridge formation with amorphous structure with no support in the dentin walls of the channel. The dentin bridges were porous with no distinct border between the bridge and the pulpal tissue. Pathological resorption of the pulp was also evident [Fig. 9].

Volume 5 Issue 7, July 2016 www.ijsr.net 


\section{International Journal of Science and Research (IJSR) ISSN (Online): 2319-7064}

Index Copernicus Value (2013): 6.14 | Impact Factor (2015): 6.391

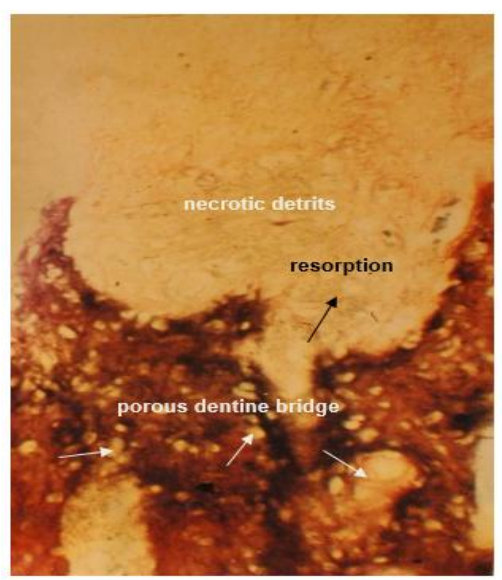

Figure 9: 3 months after treatment showing porous dentin bridge, resoprtion and necrotic debris dyed with Van Gieson

\section{Discussion}

In this study, vital amputation of coronary pulp of the teeth was performed until the entrance of the radicular channel in piglets after which artificial pulpitis was created and treated with different preparations of Albanian propolis. We assumed that, the radicular pulp obtained was vital and not inflamed. The propolis was expected to eliminate the traumatic infection caused by the dental bur. Based on the results of this study, since the application of propolis in the 3 groups $\left(2^{\text {nd }}, 3^{\text {rd }}\right.$, and $4^{\text {th }}$ groups $)$ showed histological differentiation significantly compared to the control group, the hypothesis could be partially accepted.

Several previous studies were performed only in complete sterile conditions. In fact, it is impossible to diagnose inflammatory complications in the teeth that were covered. Therefore, the critical evaluation of the healing in amputated pulp after covering could only be performed histologically. In this study, three months after application, the pulp in the teeth treated with pure propolis, dentin bridges were formed, with odontoblastic profile with no inflammatory response. This might be attributed to the anti-inflammatory properties of flavonoids and caffeic acid present in the composition of the propolis that are well-known to decrease inflammation. Increasing of propolis concentration to $20 \%$ in ethanol mixed with zinc oxide even signified more promising results. The dentin barrier quality observed in radiological and histological examinations, confirmed no inflammation accompanied with high quality dentin barrier formation.

Although antibacterial properties of the pastes could be verified and effective results of the use of propolis could be observed, in this study, the healing of the teeth could not be excluded based on immune capabilities of the vital pulp. Sterile inflammatory phases are typically observed during the first months after vital amputation but the results in this study already after 3 months verified the regenerative effects of the propolis pastes used.

Numerous previous studies reported necrosis with the use of calcium hydroxide. ${ }^{[3],[8],[9],[13],[14],[17]}$ The results obtained from the fifth group where $\mathrm{Ca}(\mathrm{OH})_{2}+30 \%$ oily propolis was used in this study have highlighted resorption that could be due to the presence of calcium hydroxide in the composition of the paste.
According to the methodology employed in this study, the inflammation was identified already two hours after the application of the pastes. It can be this stated that the method used to injure and inoculate the microbial flora caused active acute hyperemia. The existence of experimental pulpal inflammation was recognized by not only erythrocytes but also with the presence of polymorphonuclear leukocytes.

In this in vivo study piglets were used due to the closest structural resemblance of their teeth to the human teeth, while many previous studies were conducted on mice, dogs, monkeys, and humans. ${ }^{[7],[8],[17]}$

Propolis was mixed with zinc oxide in this study that is a neutral powder commonly used in dentistry. The absorbance capabilities of $\mathrm{ZnO}$ allowed to removing the ethanol from the composition. The anti-inflammatory regenerating capabilities of propolis were not evident in group 2 where pure propolis was used and not mixed with $\mathrm{ZnO}$.

\section{Conclusions}

After vital amputation of the pulp, application of Albanian propolis showed anti-inflammatory and regenerative effects creating dentin barrier after 3 months of treatment in vivo in piglets. These results were more expressed in the group containing $20 \%$ propolis in ethanol $+\mathrm{ZnO}$.

\section{Future Scope}

Future studies should elaborate clinical use of the compounds tested in this study. The potential advantages of the use of propolis should be followed in endodontically treated teeth clinically.

\section{References}

[1] Almas K, Dahlan A, Mahmoud A. Propolis as a natural remedy: an update. Saudi Dent J 2001;13:45-49.

[2] Al-Shaher A, Wallace J, Agarwal S, Bretz W, Baugh D. Effect of propolis on human fibroblasts from the pulp and periodontal ligament. J Endod 2004;30:359-361.

[3] Attalla MN, Noujaim AA. Role of calcium hydroxide in the formation of reparative dentine. J Canad Dent Assoc 1969;35:267-269.

[4] Betoni JE, Mantovani RP, Barbosa LN, Di Stasi LC, Fernandes Júnior A. Synergism between plant extract and antimicrobial drugs used on Staphylococcus aureus diseases. Mem Inst Oswaldo Cruz 2006;101:387-390.

[5] Borrelli F, Maffia P, Pinto L,. Phytochemical compounds involved in the anti-inflammatory effect of propolis extract. Fitoterapia 2002;73:S53-63.

[6] Burdock GA. Review of biological properties and toxicity of bee propolis (propolis). Food Chem Toxicol 1998;36:347-363.

[7] Chopra S, Pillai KK, Husain SZ, Giri DK. Propolis protects against doxorubicin-induced myocardiopathy in rats. Exp Mol Pathol 1995;62:190-198.

[8] Cox CF, Bergenholtz G, Fitzgerald M, Heys DR, Heys RJ, Avery JK, Baker JA. Capping of the dental pulp mechanically exposed to the oral microflora - a 5-week 


\section{International Journal of Science and Research (IJSR) \\ ISSN (Online): 2319-7064}

Index Copernicus Value (2013): 6.14 | Impact Factor (2015): 6.391

observation of wound healing in the monkey. J Oral Pathol 1982;11:327-339.

[9] Cvek M. A clinical report on partial pulpotomy and capping with calcium hydroxide in permanent incisors with complicated crown fracture. $\mathrm{J}$ Endodont 1978;4:232-237.

[10]Fernandes Júnior A, Balestrin ECD, Cunha MRLS. Atividade anti Staphylococcus aureus de extratos de própolis (EP) de Apis mellifera preparados com diferentes concentrações de etanol. Rev Ciênc Farm 2003;24:147-152.

[11]Fernandes Júnior A, Balestrin EC, Betoni JE, Orsi Rde O, da Cunha Mde L, Montelli AC. Propolis: antiStaphylococcus aureus activity and synergism with antimicrobial drugs. Mem Inst Oswaldo Cruz 2005; 100:563-566.

[12] Garedew A, Schmolz E, Lamprecht I. Microbiological and calorimetric investigations on the antimicrobial actions of different propolis extracts: an in vitro approach. Thermochimica Acta 2004;422:115-124.

[13] Gebaraa EC, Pustiglioni AN, de Lima LA, Mayer MP. Propolis extract as an adjuvant to periodontal treatment. Oral Health Prev Dent 2003;1:29-35.

[14] Gonsalez GZ, Orsi RO, Fernandes Júnior A, Rodrigues $\mathrm{P}$, Funari SRC. Antibacterial activity of propolis collected in different regions of Brazil. J Venom Anim Toxins incl Trop Dis 2006;12:2762-84.

[15] Koo H, Rosalen PL, Cury JA, Ambrosano GM, et al. Effect of a new variety of Apis mellifera propolis on mutans streptococci. Curr Microbiol 2000;41:192-196.

[16] Kujumgiev A, Tsvetkova I, Serkedjieva Y, Bankova V, Christov R, Popov S. Antibacterial, antifungal and antiviral activity of propolis of different geographic origin. J Ethnopharmacol 1999;64:235-240.

[17] Lima RV, Esmeraldo MR, de Carvalho MG, de Oliveira PT, de Carvalho RA, da Silva FL Jr, de Brito Costa EM. Pulp repair after pulpotomy using different pulp capping agents: a comparative histologic analysis. Aust. Dent. J 2011;33:14-18.

\section{Author Profile}

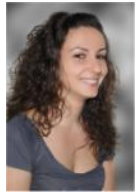

Aida Meto is University of Aldent, Faculty of Medicine, Department of Dentistry, Section of Endodontics, Histological and Bacteriological Laboratory, Tirana, Albania.

Agron Meto is University of Aldent, Faculty of Medicine, Department of Dentistry, Section of Endodontics, Histological and Bacteriological Laboratory, Tirana, Albania.

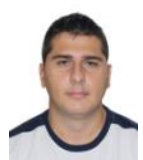

Emiljano Tragaj is from University of Aldent, Faculty of Medicine, Department of Dentistry, Section of Endodontics, Histological and Bacteriological Laboratory, Tirana, Albania.

Mutlu Özcan is in University of Zurich, Dental Materials Unit, Center for Dental and Oral Medicine, Clinic for Fixed and Removable Prosthodontics and Dental Materials Science, Zurich, Switzerland.

Volume 5 Issue 7, July 2016 www.ijsr.net 